Article

\title{
Breakage Characterization of Grinding Media Based on Energy Consumption and Particle Size Distribution: Hexagons versus Cylpebs
}

\author{
Caibin $\mathrm{Wu}^{1,2, *}$, Ningning Liao ${ }^{1, *}$, Guiming Shi ${ }^{1,2}$ and Liangliang $\mathrm{Zhu}{ }^{1}$ \\ 1 School of Resources and Environmental Engineering, Jiangxi University of Science and Technology, \\ Ganzhou 341000, China; sgm_008@yxnu.edu.cn (G.S.); abc151007@163.com (L.Z.) \\ 2 Jiangxi Key Laboratory of Mining Engineering, Jiangxi University of Science and Technology, \\ Ganzhou 341000, China \\ * $\quad$ Correspondence: caibin.wu@jxust.edu.cn (C.W.); liaoningning@yeah.net (N.L.); Tel.: +86-0797-831-2482 (C.W.)
}

Received: 2 October 2018; Accepted: 10 November 2018; Published: 13 November 2018

check for updates

\begin{abstract}
The grinding performance of hexagon grinding media particles has been compared with that of cylpebs grinding media particles. A batch grinding test was conducted using equal masses of hexagons and cylpebs. The particle size distribution and energy consumption during grinding of the ground product were analyzed, and the relationships among the specific surface area, bulk density, energy consumption, and $t_{10}$ value are discussed. Under the same grinding conditions, the grinding capacity of hexagons was inferior to that of cylpebs. However, as the particle size of the feed became finer, the grinding effect of hexagons became more apparent. At the same time, the qualified particles content in the ground product was higher when using hexagons than when using cylpebs. The relationship between the specific surface area and energy consumption during grinding was consistent with the regular pattern of grinding fineness and energy consumption. In addition, the bulk density of minerals decreases with an increase in grinding energy. The same conclusion was obtained when $-0.425 \mathrm{~mm}$ tungsten ore was used as a sample for validation. The flotation experiment result has carried out that hexagons as grinding media have a better flotation indicator than cylpebs in the same grinding fineness. It is demonstrated that although the grinding capacity of hexagons is inferior to that of cylpebs, less overgrinding occurs when using hexagons than when using cylpebs. For tungsten ore grinding, hexagons act as a finer grinding media than cylpebs.
\end{abstract}

Keywords: cylpebs; hexagons; bulk density; specific surface area; grinding energy consumption; size distribution characteristics

\section{Introduction}

The grinding media that is most often employed in grinding is steel balls. Since the 1950s, other types of grinding media, such as cylinders, cones, hexagons, cylpebs, and anisotropic media, have been used in the grinding process [1]. It is generally accepted that grinding is a random process in which the degree of grinding depends on the probability of the mineral entering into the region between the grinding media particles (the "probability of contact"), and the probability of breakage of the mineral after contact with the grinding media (the "probability of breakage") [2,3]. Generally, the contact probability is related to the specific surface area of the grinding media, while the breakage probability depends on the mass of the grinding media. During the breaking of coarse particles in the course of grinding, the process is dominated by the breakage probability, whereas, when fine particles are being broken, the contact probability becomes more significant than the breakage probability.

Thus, the ideal media for the grinding process is one that provides for a large enough surface area while satisfying the crushing force precondition. Compared with steel balls, the advantages of 
cylinders are their large surface area and mode of contact. In contrast to spherical steel balls, cylinders are capable of line contact in addition to point contact. Furthermore, the particle size of the crushed product is uniform $[4,5]$. Herbst employed an intermittent standard energy grinding model to compare the grinding efficiency of steel balls with that of truncated cones as grinding media. While there was no difference in the breakage functions of steel balls and truncated cones, a difference was observed in the specific selectivity function. The main reason was that the breakage probability is affected by the differences in the types of grinding media used in the grinding process [6]. Convex-concave balls have a smaller volume than steel balls of the same diameter and a smaller mass than steel balls of the same surface area; hence, their specific surface area is larger than that of steel balls. A judiciously chosen mixture of steel balls and concave balls permits effective selectivity in grinding. However, when the proportion of convex-concave balls exceeds a certain proportion, the irregularity in the relative motion of the balls increases, and the grinding efficiency cannot be improved beyond a certain limit. Thus, it can be concluded that improvements in grinding efficiency are related to the size of the specific surface area of convex-concave balls [7]. According to Shi [8], the grinding efficiency of steel cylpebs and steel balls is affected by the mass, surface area, and geometry of the grinding media.

There are three major theories that explain power consumption during mineral crushing in grinding. To relate energy consumption and grinding fineness in the grinding process, Rittinger [9] proposed that the amount of energy consumed during mineral crushing is proportional to the amount of fresh surface area on the mineral. Kick [10], however, was of the opinion that the amount of energy consumed during mineral crushing is proportional to the change in volume of the mineral. Later, Bond [11] suggested that energy consumption during mineral crushing is related to the mineral's feed size and product size. Stamboliadis $[12,13]$ further validated the feasibility of the three major power consumption theories. The amount of energy the mineral grinding process consumes has a certain relationship with the specific surface area and particle size distribution of the ground product. Stamboliadis $[14,15]$ found that the specific surface area of the ground product increased with an increase in specific energy. Compared with the feed, the ground product was found to change not only with respect to the particle size and specific surface area, but also the bulk density. Thus, there is a need to thoroughly explore the relationships between the specific surface area, bulk density, and energy consumption with the particle size composition of the ground product obtained using hexagons and cylpebs.

The aforementioned studies are all part of the ongoing search for a grinding media with a large specific surface area for relatively the same weight. Shi [16] developed the grinding media known as hexagons, which mainly undergo surface and line contact during grinding. The surface contact among hexagons improves the conditions for effective comminution. Due to the hexagons' larger specific surface area, which increases the uniformity of the ground product granules, the selectivity of the grinding process is obviously better than that obtained when using cylpebs. Hence, hexagons are suitable for the grinding of brittle minerals, such as tungsten and tin ore. In this study, we use single-sized feeds of $1.18-2.00 \mathrm{~mm}, 0.60-1.18 \mathrm{~mm}$, and $0.30-0.60 \mathrm{~mm}$, and industrial second classification underflow as a sample. Equal masses of hexagons and cylpebs were used for the batch grinding test. The energy consumption of the grinding process was recorded and the JK size-dependent breakage model was used to fit the experimental data. The particle size distribution and energy consumption during grinding of the ground product were analyzed and the relationships between the specific surface area, bulk density, energy consumption, and $t_{10}$ value are discussed.

\section{Materials and Methods}

\subsection{Materials and Grinding Media}

Tungsten ore was obtained from Hunan Shizhuyuan Nonferrous Metals Co., Ltd., Chenzhou, China. Tungsten ore samples of size $1.18-2.00 \mathrm{~mm}, 0.60-1.18 \mathrm{~mm}$, and $0.30-0.60 \mathrm{~mm}$ were prepared by crushing and screening. In addition, particles of size less than $0.425 \mathrm{~mm}$ from the industrial 
second-classification underflow samples were used for validation. The cylpebs that were used in the experiment had a diameter of $36 \mathrm{~mm}$ and a length of $48 \mathrm{~mm}$. The total mass of used cylpebs was 10,671 g.

Compared with cylpebs, hexagons have a bottom side length of $22 \mathrm{~mm}$, a side length of $48 \mathrm{~mm}$, and a side width of $36 \mathrm{~mm}$ as shown in Figure 1. The grinding media that were used in the experiment had the same total mass. The differences in the physical properties of cylpebs and hexagons are shown in Table 1. The specific surface area of hexagons is as large as that of cylpebs having the same diameter. Since the mass of a single hexagon is slightly larger than that of a single cylpebs, the number of hexagons is less than that of cylpebs. However, the surface area of each hexagon is $13.2 \%$ greater than the surface area of a cylpebs, and the total surface area is $2.28 \%$ greater than that of cylpebs. Regarding the contact mechanism between the grinding media and the mineral, grinding with cylpebs is due mainly to line contact and grinding with hexagons due to surface contact that is supplemented by line contact.
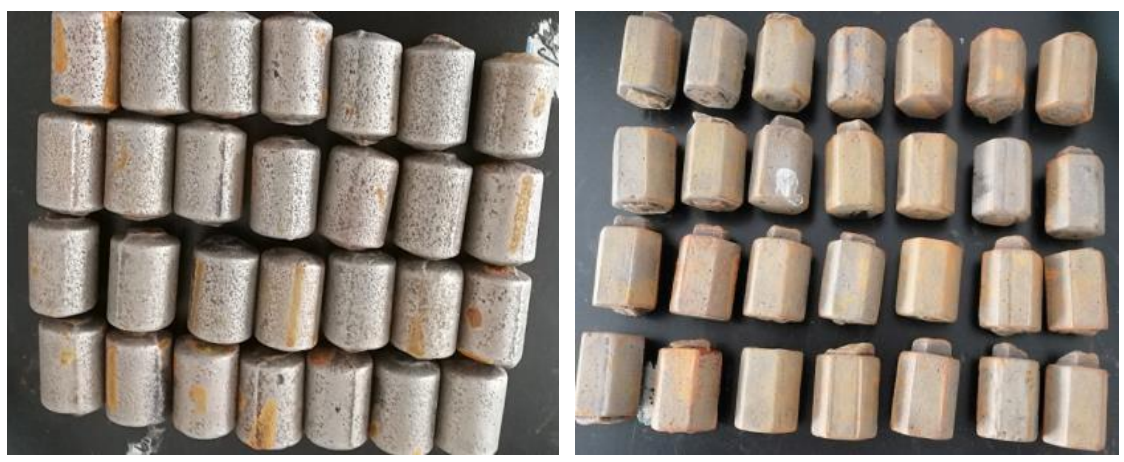

Figure 1. Photographs of grinding media: (left) cylpebs; (right) hexagons.

Table 1. Physical properties of grinding media.

\begin{tabular}{ccc}
\hline Grinding Media & Cylpebs & Hexagons \\
\hline Dimension $(\mathrm{mm})$ & $\Phi 48 \times 36$ & $\Phi 48 \times 36$ \\
Total mass $(\mathrm{g})$ & 10,671 & 10,664 \\
Single mass $(\mathrm{g})$ & 338.12 & 390.5 \\
Surface area $\left(\mathrm{cm}^{2}\right)$ & 74.61 & 84.49 \\
Specific surface $\left(\mathrm{cm}^{2} / \mathrm{g}\right)$ & 0.22 & 0.22 \\
Grinding media number & 31 & 28 \\
Total surface area $\left(\mathrm{cm}^{2}\right)$ & 2312.91 & 2365.72 \\
Bulk density $\left(\mathrm{g} / \mathrm{cm}^{3}\right)$ & 4.91 & 4.90 \\
\hline
\end{tabular}

\subsection{Experimental Methods}

Experiments were performed using an XMQ- $\Phi 240 \mathrm{~mm} \times 90 \mathrm{~mm}$ conical ball mill made by Wuhan Exploring Machinery Factory (Wuhan, China). The intermediate cylinder part of mill has a diameter of $240 \mathrm{~mm}$ and length of $90 \mathrm{~mm}$. The total internal volume of mill is $6.25 \mathrm{dm}^{3}$ and rotation speed of mill is $96 \mathrm{r} / \mathrm{min}$. The conical ball mill is shown in Figure 2. The batch grinding test was performed in the abovementioned conical ball mill. In all grinding tests, the grinding pulp density was kept at $65 \%$, the media filling rate at $35 \%$, and the feed mass at $500 \mathrm{~g}$, and only the grinding time was varied. Batch grinding experiments were carried out using cylpebs and hexagons as grinding media; the tests were $1 \mathrm{~min}, 2 \mathrm{~min}, 3 \mathrm{~min}$, and $4 \mathrm{~min}$ in duration. The energy used during the grinding process was recorded in real time through a power recorder to calculate the energy consumption of the grinding process. After a grinding test was completed, the ground product was dried, coned, and quartered to prepare a $125 \mathrm{~g}$ sample for screening. A standard sieve set with a sieve order of $\sqrt{ } 2$ was used for screening. A Dandong Diffraction Particle Sizer was used to analyze whether the particle size of the ground product was less than $0.038 \mathrm{~mm}$. Finally, the particle size distribution of the ground product was calculated. 


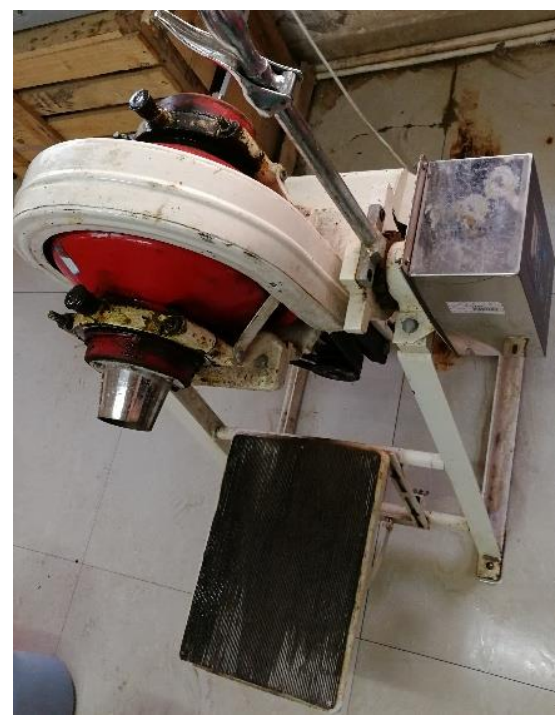

Figure 2. Conical ball mill.

The grinding equipment is shown in Figure 3, the grinding test equipment consists of a laboratory conical ball mill, a voltage regulator, a power meter. A computer interface system with SerialPortUtility software was employed to log the average active powder data during the test.

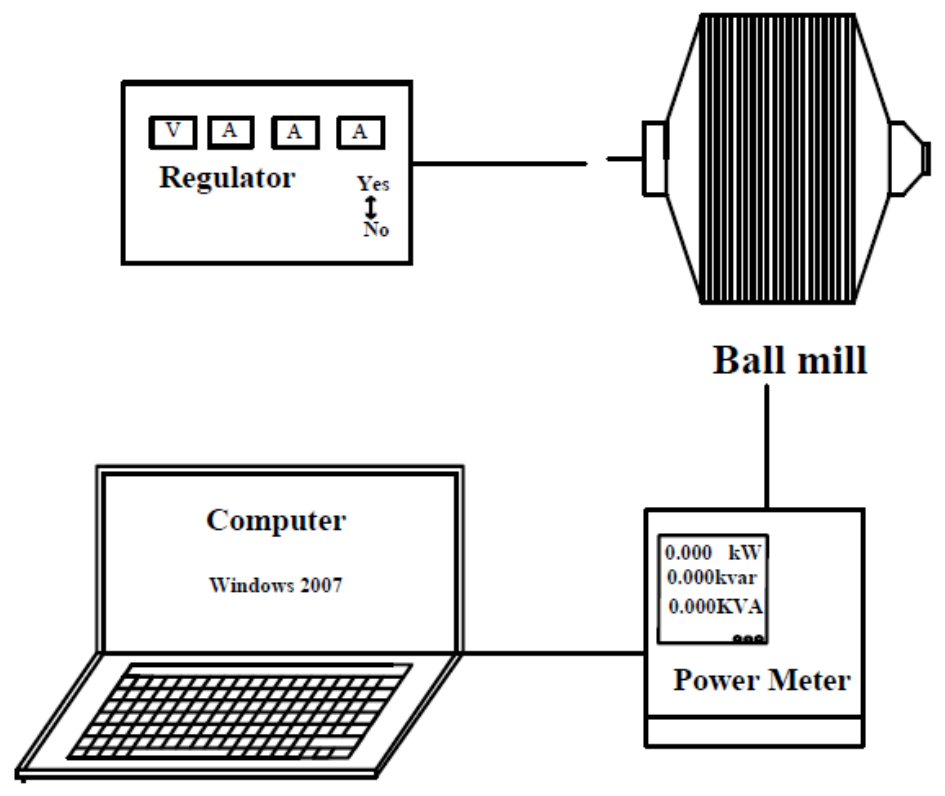

Figure 3. Conical ball mill grinding device sketch.

The specific comminution energy was determined from the average active power, grinding time, and sample mass, as shown in the equation:

$$
\mathrm{E}_{\mathrm{cs}}=\frac{\overline{\mathrm{P}} \times \mathrm{t} \times 60 \times 10^{6}}{3600 \times \mathrm{m}}
$$

where $E_{c s}$ is the specific comminution energy $(\mathrm{kWh} / \mathrm{t}) ; \mathrm{m}$ is the mass of the tested sample $(\mathrm{g})$; $\mathrm{t}$ is the total grinding time ( $\mathrm{min}) ; 10^{6}$ is the mass unit conversion from grams to tons; the constant 3600 is the time unit conversion from seconds to hours; and $\overline{\mathrm{P}}$ is net average active power $(\mathrm{kW})$, which is determined by:

$$
\overline{\mathrm{P}}=\overline{\mathrm{P}}_{1}-\overline{\mathrm{P}}_{0}
$$


where $\overline{\mathrm{P}}_{1}$ is the loaded average active power $(\mathrm{kW})$, and $\overline{\mathrm{P}}_{0}$ is the unloaded average active power $(\mathrm{kW})$. In this paper, $\overline{\mathrm{P}}_{1}$ and $\overline{\mathrm{P}}_{0}$ can be measured in the experiment, $\overline{\mathrm{P}}$ and $\mathrm{E}_{\mathrm{cs}}$ can be calculated by Equations (1) and (2).

\subsection{Confidence Analysis of Experiments}

Confidence analyses with statistically significant differences at the $95 \%$ confidence interval is significant in the experiments [17-19]. Test repeats were carried out for a grinding duration of $2 \mathrm{~min}$ with cylpebs and hexagons, respectively. The energy consumption and $t_{10}$ value of the grinding process in each experiment was recorded and calculated, and a confidence analysis of the test data was performed. Table 2 shows the results of the specific energy and $t_{10}$ values in the test repeats. It can be observed from the table that the data from these tests have good repeatability and high reliability. There is also a certain degree of difference at the $95 \%$ confidence level between cylpebs and hexagons; however, all of the differences are within a $5 \%$ confidence level, indicating that the data are reliable.

Table 2. The $95 \%$ confidence limits associated with the specific energy and $t_{10}$ values.

\begin{tabular}{ccccc}
\hline \multicolumn{1}{c}{ Size } & \multicolumn{3}{c}{$\mathbf{0 . 6 - 0 . 3} \mathbf{~ m m}$} \\
\hline Grinding Media & \multicolumn{2}{c}{ Cylpebs } & \multicolumn{2}{c}{ Hexagons } \\
\cline { 2 - 5 } & $\mathbf{E}_{\mathbf{c s}} \mathbf{( k W h / t )}$ & $\mathbf{t}_{\mathbf{1 0}} \mathbf{( \% )}$ & $\mathbf{E}_{\mathbf{c s}} \mathbf{( k W h / \mathbf { t } )}$ & $\mathbf{t}_{\mathbf{1 0}} \mathbf{( \% )}$ \\
\hline Repeat 1 & 0.82 & 13.67 & 0.69 & 9.36 \\
Repeat 2 & 0.86 & 13.40 & 0.65 & 9.68 \\
Repeat 3 & 0.80 & 13.10 & 0.68 & 9.74 \\
Mean & 0.83 & 13.39 & 0.67 & 9.60 \\
95\% Confidence limit & 0.04 & 0.32 & 0.02 & 0.22 \\
95\% Confidence limit relative to the mean (\%) & 4.18 & 2.41 & 3.50 & 2.27 \\
\hline
\end{tabular}

\section{Results and Discussion}

\subsection{Size Distribution Characterization of Ground Product}

For the grinding times of $1 \mathrm{~min}$ and $4 \mathrm{~min}$, the particle size distribution of the ground product obtained using cylpebs and hexagons as grinding media is shown in Figure 4.

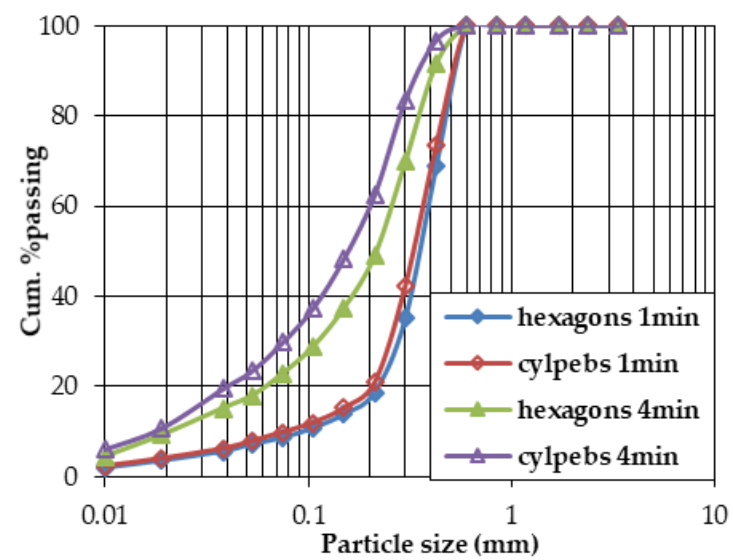

Figure 4. Size distributions of ground product using hexagons and cylpebs as grinding media.

Figure 4 indicates that cylpebs and hexagons have a similar grinding particle size distribution. From the point of view of the fineness of grinding, the difference in fineness between cylpebs and hexagons increases with an increase in grinding time. From point of view of the $\mathrm{P}_{80}$ sizes (the $80 \%$ passing size of product), as the grinding time increases, the differences in the $\mathrm{P}_{80}$ sizes increase. Therefore, considering only the fineness index, the grinding capacity of hexagons is obviously inferior to that of cylpebs. 
For a feed of the same particle size, hexagons and cylpebs have a similar particle size distribution. The hexagons' ability to grind fine particle materials continues to increase. The particle size distribution of the ground product under three single-size feeds and a grinding duration of 2 min is shown in Figure 5. It shows that feeds with finer particle sizes tend to generate more products having $-0.075 \mathrm{~mm}$ content, and the difference in the grinding effect of fine particle grades between cylpebs and hexagons is reduced.

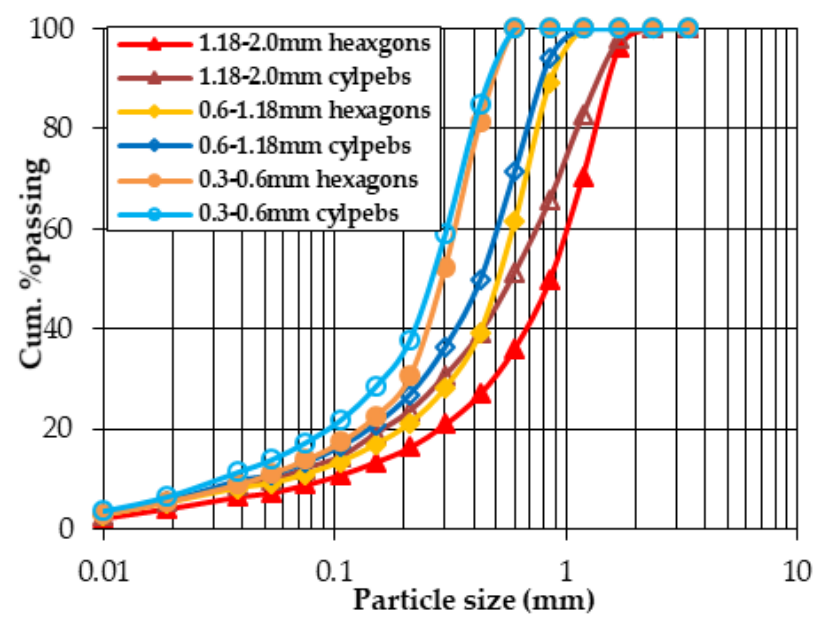

Figure 5. Size distributions of ground product with three single-sized feeds and a 2-min grinding duration.

\subsection{Energy Consumption Characterization of the Grinding Process}

For the purpose of comparing the energy consumption distribution of cylpebs and hexagons, the $t_{10}$ value (the cumulative mass percentage of the product that passes $10 \%$ of the initial feed size) was used as a comparison index for grinding fineness, and the mass percentage of $-0.01 \mathrm{~mm}$ was used as an overgrinding indicator. The relationship between the $t_{10}$ value and specific energy is shown in Figure 6, and the relationship between the mass percentage of $-0.01 \mathrm{~mm}$ and specific energy is shown in Figure 7.

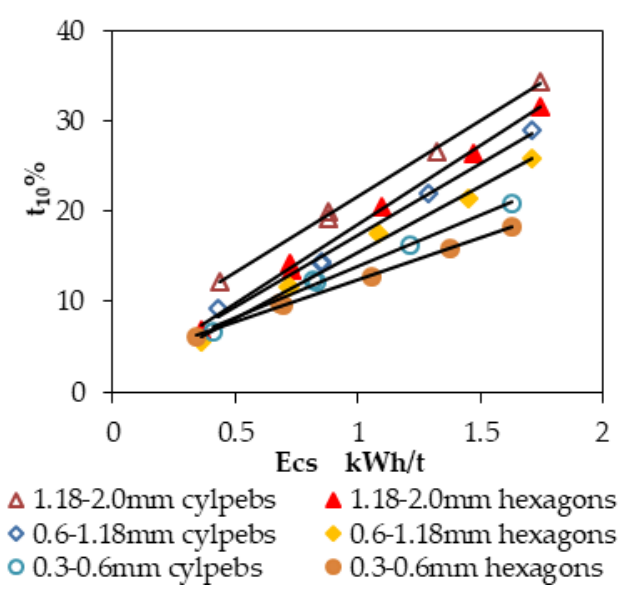

Figure 6. $\mathrm{t}_{10}$ in relation to specific energy. 


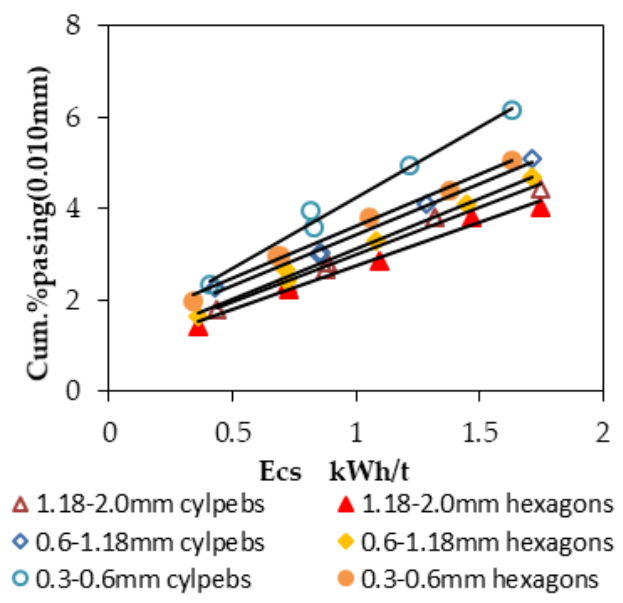

Figure 7. Relationship between the mass percentage of particles less than $0.01 \mathrm{~mm}$ and specific energy.

Shi and Kojovic developed a new JK breakage model, which considers the particle size effect and is based on experimental results, to describe the degree of fine particle breakage [20-24]. Its expression is as follows:

$$
\mathrm{t}_{10}=\mathrm{M}\left\{1-\exp \left[-\mathrm{f}_{\mathrm{mat}} \cdot \mathrm{x} \cdot \mathrm{k}\left(\mathrm{E}-\mathrm{E}_{\min }\right)\right]\right\}
$$

where $t_{10}$ is a breakage index, which is defined as the cumulative mass percentage of the product that passes $10 \%$ of the initial feed size; $\mathrm{M}(\%)$ represents the maximum $\mathrm{t}_{10}$ value at which material breakage occurs; $x(\mathrm{~m})$ the original particle size; $\mathrm{E}(\mathrm{J} / \mathrm{kg})$ is the mass-specific impact energy in the test; and $\mathrm{f}_{\mathrm{mat}}$ is a model parameter, which is determined by $f_{\text {mat }}=p \cdot d^{-q}$. where $d$ is the particle size $(\mathrm{mm})$.

What's more, the JK size-dependent breakage model takes the form

$$
\mathrm{t}_{10}=\mathrm{M}\left\{1-\exp \left[-3.6 \cdot \mathrm{p} \cdot \mathrm{d}^{1-\mathrm{q}} \cdot \mathrm{k}\left(\mathrm{E}_{\mathrm{cs}}-\mathrm{E}_{0}\right)\right]\right\}
$$

where $E_{\mathrm{cs}}(\mathrm{kWh} / \mathrm{t})$ is the mass-specific impact energy of the test, and $E_{0}(\mathrm{kWh} / \mathrm{t})$ is the energy threshold.

In this study, $\mathrm{k}$ and $\mathrm{E}_{\min }$ are set to 1 and 0 , respectively. The parameters $\mathrm{M}, \mathrm{p}$, and $\mathrm{q}$ can be obtained simultaneously from the experimental data after breakage. $\mathrm{d}$ is the particle size of the initial particle in millimeters. The $\mathrm{d}$ value pertinent to this experiment is $2 \mathrm{~mm}$. The fitted JK breakage model curves for steel cylpebs and hexagons are shown in Figure 8, respectively. The JK breakage models for cylpebs and hexagons are as follows:
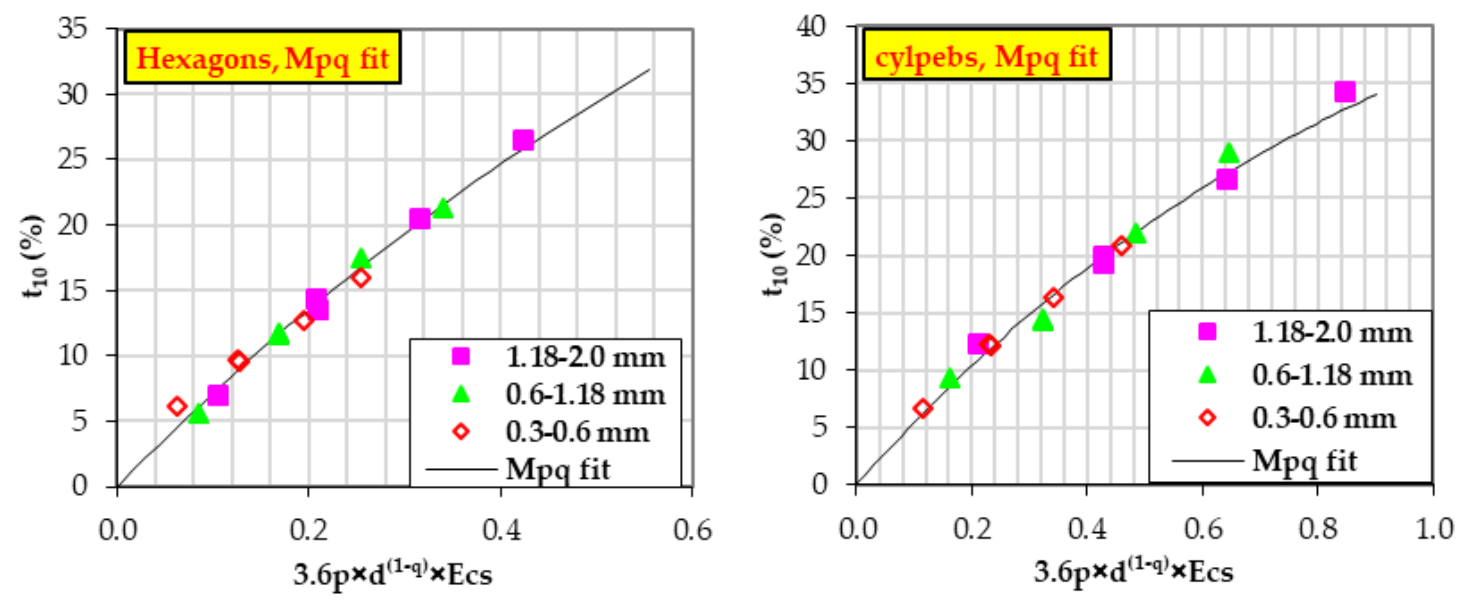

Figure 8. JK size-dependent model fitting with the test data.

For steel cylpebs, the values for parameters $\mathrm{M}$, p, and $\mathrm{q}$ are $57.3,0.113$, and 0.576 , respectively, and the corresponding expression is given by: $\mathrm{t}_{10}=57.3\{1-\exp [-0.076 \cdot \mathrm{x} \cdot \mathrm{E}]\}$; 
For hexagons, the values for parameters $\mathrm{M}, \mathrm{p}$, and $\mathrm{q}$ are $74.7,0.069$, and 0.656 , respectively, and the corresponding expression is given by: $\mathrm{t}_{10}=74.7\{1-\exp [-0.044 \cdot \mathrm{x} \cdot \mathrm{E}]\}$.

When the original particle size is $1 \mathrm{~m}$, the specific energy input is $1 \mathrm{~J} / \mathrm{kg}$, and the $t_{10}$ of cylpebs and hexagons is 4.19 and 3.22, respectively. The JK size-dependent breakage model fitting data indicate that the hexagons and cylpebs have a similar grinding function.

As shown in Figure 6, the $t_{10}$ value decreases as the grain size of the feed decreases. With the same input energy and the same cylpebs mass, when the particle size decreases, the $t_{10}$ values decrease rapidly. The same regular trend is exhibited by the hexagons as well. Comparing cylpebs and hexagons, regardless of the specific energy being the same and the particle size of the feed, cylpebs have a higher $t_{10}$ value than hexagons, and can reach up to $3.09 \%$ with a change in the particle size of the feed.

From Figure 7, it can be concluded that the mass percentage of particles less than $0.01 \mathrm{~mm}$ in the ground product increases with a decrease in feed particle size. With the same input energy and the same cylpebs mass, the mass percentage of particles less than $0.01 \mathrm{~mm}$ in the ground product increases with a decrease in particle size. A similar trend is exhibited by the hexagons as well. Comparing cylpebs and hexagons, regardless of the fact that the specific energy and particle size of the feed are the same, the mass percentage of particles less than $0.01 \mathrm{~mm}$ in the ground product by cylpebs is higher than that by hexagons, and can reach up to $0.66 \%$ with a change in the particle size of the feed.

\subsection{Relationship between Specific Surface Area and Energy Consumption}

Stamboliadis deduced the specific surface area formula for a specific ground product [15], which is expressed as follows:

$$
\mathrm{ss}=\mathrm{f} / \mathrm{k} \cdot \rho \times\left(\sum_{1}^{\mathrm{n}+1} \frac{\Delta \mathrm{pi}}{\mathrm{di}} / \sum_{1}^{\mathrm{n}+1} \Delta \mathrm{pi}\right)
$$

where ss is the calculated specific surface area for a particular material in $\mathrm{m}^{2} / \mathrm{kg}$; $\mathrm{f}$ is the surface coefficient (for spherical particles, $\mathrm{f}=\pi$ ); $\mathrm{k}$ is the volume factor (for spherical particles, $\mathrm{k}=\pi / 6$ ); $\mathrm{q}$ is the density of the material in $\mathrm{kg} / \mathrm{m}^{3}$; the $\mathrm{n}$ sieves with a sieve order of $\sqrt{ } 2$ are divided into $\mathrm{n}+1$ size classes; $\Delta p_{i}$ is the mass fraction (in \%) of $t$ in the size range between $x_{i}$ and $x_{i-1}$; and di is the average particle size and for the $n+1$ class material $\left(d_{n+1}=x_{n} / 2\right) m$.

In this study, the specific surface area of the material below $0.038 \mathrm{~mm}$ is calculated, and $\mathrm{k}$ and $\mathrm{f}$ are set to $\pi$ and $\pi / 6$, respectively. After the experimental determination of $q$ as $2440 \mathrm{~kg} / \mathrm{m}^{3}$, for $\mathrm{n}=2$, divisions of $-0.01 \mathrm{~mm}, 0.01-0.019 \mathrm{~mm}$, and $0.019-0.038 \mathrm{~mm}$ are made for the three particle sizes $\mathrm{d}_{1}=0.027 \mathrm{~mm}, \mathrm{~d}_{2}=0.014 \mathrm{~mm}, \mathrm{~d}_{3}=0.005 \mathrm{~mm}$. Figure 9 shows the relationship between the specific surface area and specific energy, $\mathrm{t}_{10}$, for the ground products obtained using cylpebs and hexagons.

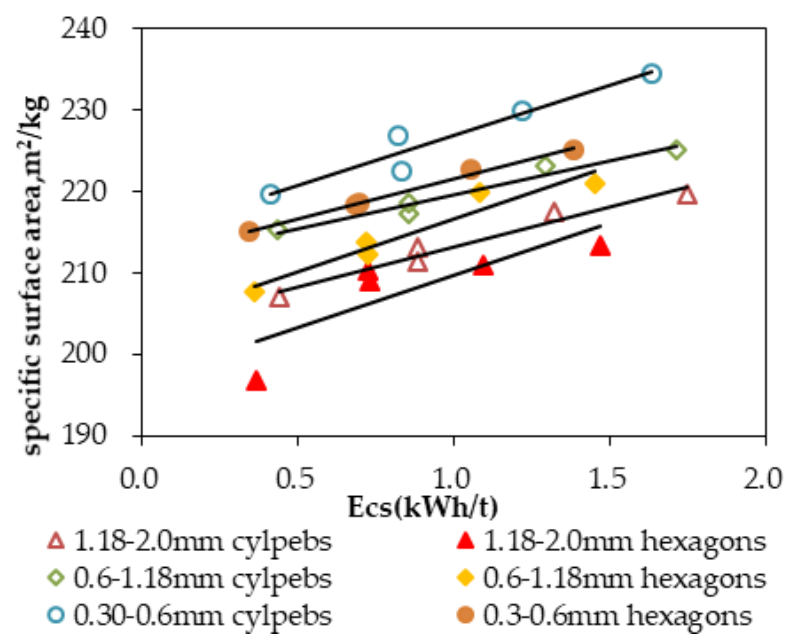

Figure 9. Relationship between specific surface area and specific energy. 
As shown in Figure 9, the specific surface area of the products obtained using hexagons and cylpebs increases with an increase in the specific energy. For the same hexagons, with the same specific energy input, the specific surface area of the minerals increases when the size of the feed decreases. Cylpebs also behave in the same manner with the same input energy and the same feed size, the ground product of cylpebs has a larger surface area than that of hexagons.

\subsection{Relationship between Bulk Density and Energy Consumption}

Historically, the quality of a ground product is measured based on grinding fineness. In addition to fineness, bulk density is one of the important indicators of grinding quality. Bulk density is depended on the relationship between the packing density and particle size distribution of ground product. The effect of particle size on packing density is medium particles $>$ large particles $>$ small particles, so medium particles percentage of product is the main influence of packing density in the overall specific volume of a particle mixture [25]. To further illustrate the relationship between bulk density and energy refer to Figure 10.

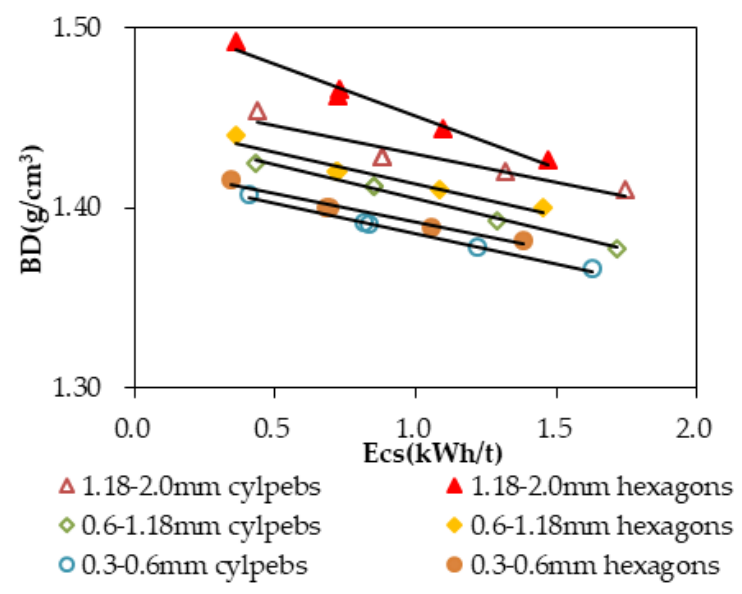

Figure 10. Relationship between specific surface area and specific energy.

From Figure 10, it can be seen that the bulk density of cylpebs- and hexagon-ground products decreases with an increase in specific energy. For the same grinding media, with the same specific energy input, the bulk density of the minerals decreases when the feed size is reduced. For the same energy input and feed size, the cylpebs-ground product has a smaller bulk density than the hexagon-ground product.

\subsection{Distribution Characteristics of Particle Size Uniformity}

The mass percentage of $0.01-0.10 \mathrm{~mm}$ is used as the index of particle size uniformity to further compare the grinding behavior of cylpebs and hexagons. Figure 11 shows the relationship between the mass percentage of $0.01-0.10 \mathrm{~mm}$ ground product, cylpebs and hexagons as grinding media, and specific energy.

Figure 11 indicates that the mass percentage of $0.01-0.10 \mathrm{~mm}$ ground product increases with a decrease in the grain size of the feed. For the same input energy, the mass percentage of $0.01-0.10 \mathrm{~mm}$ ground product increases with a decrease in particle size for the same cylpebs. Hexagons also exhibit a similar trend. Comparing the two media, regardless of the fact that the specific energy and feed particle size are the same, the mass percentage of $0.01-0.10 \mathrm{~mm}$ product ground that was obtained using cylpebs is higher than that using hexagons, and can reach up to $1.85 \%$ with a change in the particle size of the feed.

The particle size uniformity of cylpebs and hexagons is further compared at the same grinding fineness. For the $0.30-0.60 \mathrm{~mm}$ feed, the specific energy of cylpebs is $1.53 \mathrm{kWh} / \mathrm{t}$, and that of hexagons is $1.81 \mathrm{kWh} / \mathrm{t}$, at the same $\mathrm{t}_{10}$ value of $20 \%$ (Figure 6). The relative motion between cylpebs is mostly 
line contact. Collisions between hexagons, on the other hand, have line contact and surface contact, and hence the crushing force of hexagons is lower than that of cylpebs, leading to higher specific energy consumption for the hexagons at the same grinding fineness. The mass content of $0.01-0.10 \mathrm{~mm}$ cylpebs-ground material is $30.00 \%$, and that of hexagon-ground material is $31.33 \%$. This shows that the mass content of $0.01-0.10 \mathrm{~mm}$ ground product is $1.33 \%$ higher using hexagons instead of cylpebs, which indicates that grinding using hexagons produces a more uniform particle size.

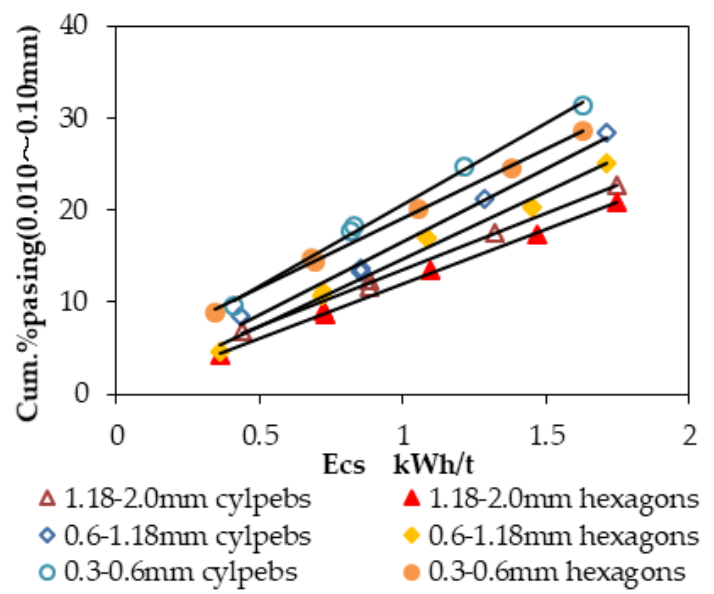

Figure 11. Mass percentage of $0.01-0.10 \mathrm{~mm}$ ground product in relation to specific energy.

\subsection{Validation Using Tungsten Ore}

Validation was carried out using industrial second-classification underflow tungsten ore from Shizhuyuan Nonferrous Metals Co., Ltd., Chenzhou, China. The actual ore contains full particles whose sizes are, for the most part, less than $0.425 \mathrm{~mm}$. For the grinding times of $1 \mathrm{~min}$ and $4 \mathrm{~min}$, the product size distribution of grinding with cylpebs and grinding with hexagons is shown in Figure 12. The relationship between the mass percentage of $0.01-0.10 \mathrm{~mm},-0.01 \mathrm{~mm}$, and the specific energy of grinding with cylpebs and grinding with hexagons is shown in Figure 13. The relationship between the specific surface area, bulk density, and specific energy is shown in Figure 14.

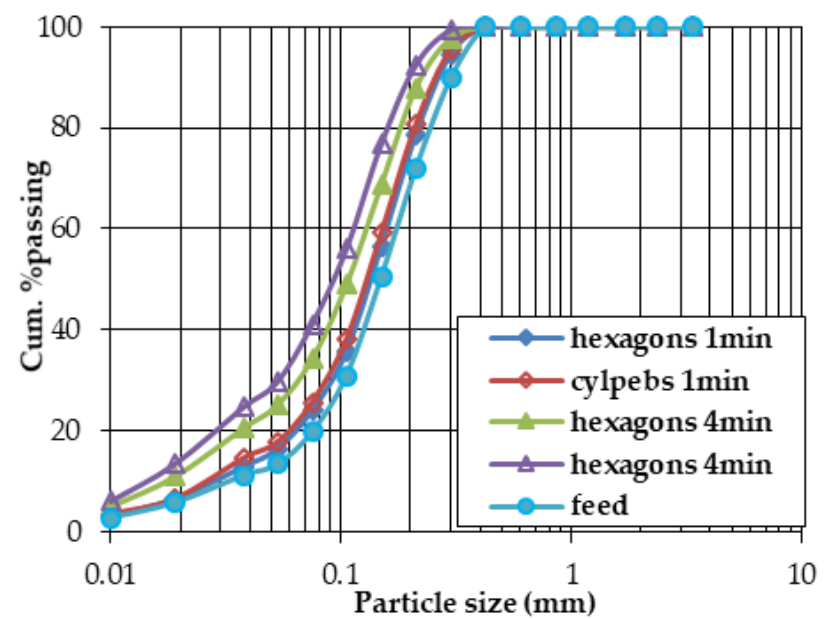

Figure 12. Size distributions of tungsten ore using hexagons and cylpebs as grinding media. 


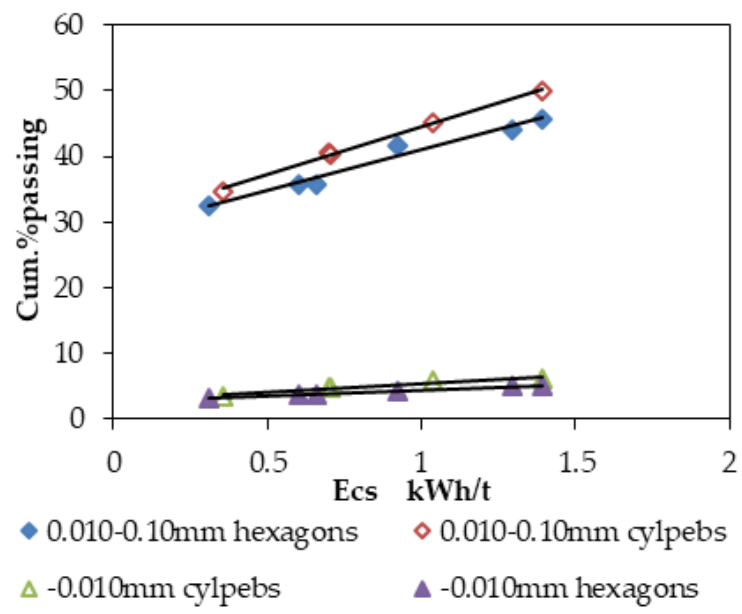

Figure 13. The mass percentage of $0.01-0.10 \mathrm{~mm}$ ground product and particles greater than $0.01 \mathrm{~mm}$ in relation to specific energy.

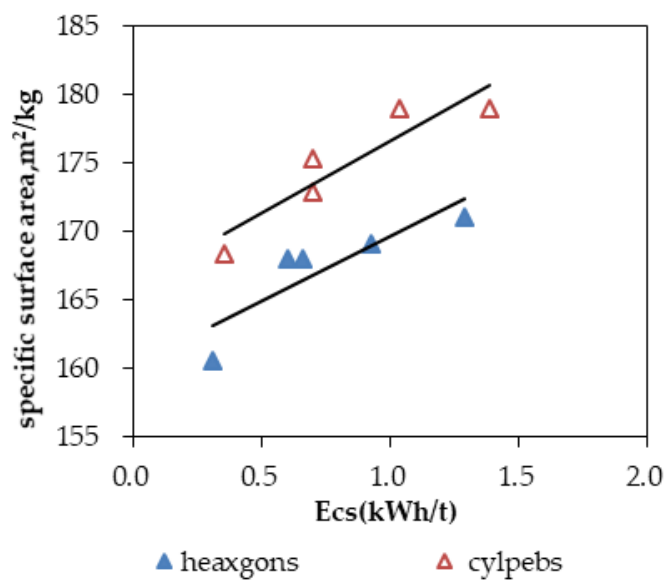

(a)

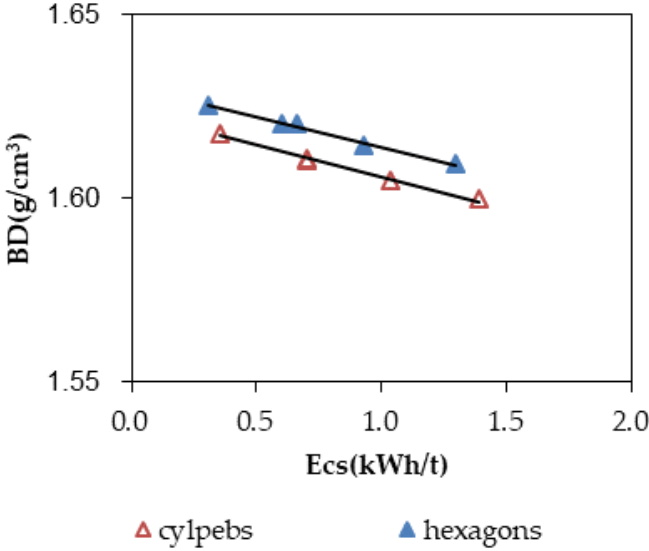

(b)

Figure 14. (a) Relationship between specific surface area and specific energy; (b) Relationship between bulk density and specific energy.

It can be seen from Figure 12 that the particle size distribution characteristics of tungsten ore have confirmed the similar particle size distribution trend for both grinding media. From the results of the $\mathrm{P}_{80}$ sizes, with the prolongation of the grinding time, the difference in $\mathrm{P}_{80}$ sizes among the three single-sized particle samples becomes significantly smaller, and this difference becomes progressively smaller as the particle size decreases.

The results indicate that, for the same input energy of $1 \mathrm{kWh} / \mathrm{t}$, the mass percentage of $0.01-0.10 \mathrm{~mm}$ cylpebs-ground product is $44.51 \%$ and the mass percentage of $0.01-0.10 \mathrm{~mm}$ hexagon-ground product is $40.97 \%$ (Figure 13). The mass content of particle size uniformity corresponding to cylpebs is only 3.54 percentage points higher than that of hexagons. This shows that the grinding capacity of hexagons is inferior to that of cylpebs. Therefore, for grinding, although hexagons and cylpebs have similar grinding effects, the grinding capacity of hexagons is lower than that of cylpebs.

On the other hand, for the same input energy of $1 \mathrm{kWh} / \mathrm{t}$, the mass percentage of particles greater than $0.01 \mathrm{~mm}$ in the hexagons-ground product is $4.45 \%$, while that in the cylpebs-ground product is $5.39 \%$. For the same input energy of $1 \mathrm{kWh} / \mathrm{t}$, the amount of overgrinding from cylpebs is $0.94 \%$ higher than that from hexagons. For the same content of qualified particle size, the uniformity is $44.51 \%$. The specific energy consumption of hexagons is increased by $1.29 \mathrm{kWh} / \mathrm{t}$, and the mass content of $-0.01 \mathrm{~mm}$ particles produced by the hexagon-ground product is increased to $5.01 \%$. The amount of overgrinding from cylpebs is $0.28 \%$ higher than that from hexagons, which indicates that hexagons 
produce less overgrinding than cylpebs. Hexagons are a better fine grinding media than cylpebs for tungsten ore grinding.

From Figure 14a,b, we can see that the relationship between the specific surface area, bulk density, and specific energy of the ground product using hexagons and cylpebs is the same as that of the grinding of single particle-size samples. The specific surface area increases as the specific energy increases, while the bulk density decreases.

In order to analyze the effect of over-grinding on the subsequent separation, we performed a flotation test. The grinding fineness of the product was $65 \%$ passing $0.075 \mathrm{~mm}$. The flotation test is carried out in the 1.5 L XFD (Wuhan Exploring Machinery Factory) flotation cell with 1992 rpm agitation rate. The $\mathrm{pH}$ conditioning is adjusted by sodium carbonate and sodium hydroxide $(800 \mathrm{~g} / \mathrm{t}+200 \mathrm{~g} / \mathrm{t})$. The tungsten collector reagent is HY-02 (Fatty acid agent). The test flow and reagents are shown in Figure 15. The flotation experiment result is shown in Table 3.

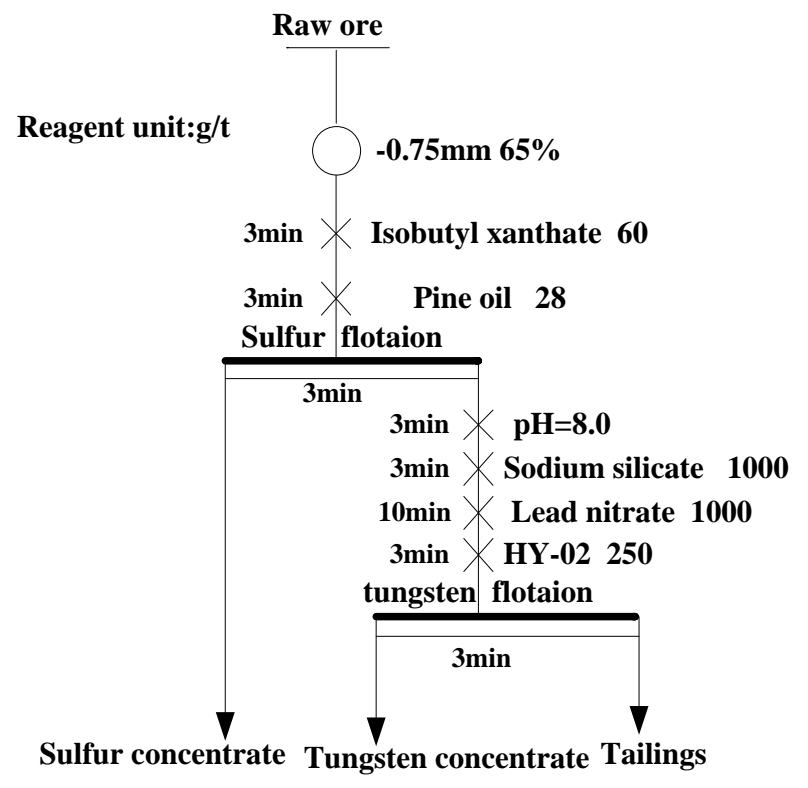

Figure 15. Flotation tests flowsheet.

Table 3. The flotation experiment result.

\begin{tabular}{ccccc}
\hline Grinding Media & Production & Yield (\%) & Tungsten Grade (\%) & Tungsten Recovery (\%) \\
\hline \multirow{4}{*}{ Cylpebs } & Sulfur concentrate & 5.30 & 0.13 & 1.06 \\
& Tungsten concentrate & 49.30 & 1.01 & 76.59 \\
& Tailings & 45.40 & 0.32 & 22.35 \\
& Feed & 100.00 & 0.65 & 100.00 \\
\hline \multirow{4}{*}{ Hexagons } & Sulfur concentrate & 4.59 & 0.08 & 0.56 \\
& Tungsten concentrate & 50.03 & 1.02 & 78.50 \\
& Tailings & 45.38 & 0.30 & 20.94 \\
& Feed & 100.00 & 0.65 & 100.00 \\
\hline
\end{tabular}

The result of Table 3 shows that the tungsten recovery of tungsten concentrate of hexagons as grinding media is $78.50 \%$, which is higher than the tungsten grade of tungsten concentrate of cylpebs as grinding media is $76.59 \%$. So, the flotation experiment result will be carried out that hexagons as grinding media have a better flotation indicator than cylpebs in the same grinding fineness.

\section{Conclusions}

The breakage behavior of a ground product is not only related to the grain size of the feed, but is also determined by the type of grinding media. Compared with cylpebs, hexagons as grinding media produce the same particle size distribution in the ground product in agreement with the JK 
size-dependent breakage model. In the grinding process, as the minerals are ground, the fineness of the minerals increases. At the same time, the specific surface area of the minerals increases, while the bulk density of the minerals decreases. The grinding fineness and the specific surface area increase with a reduction in the feed size. The bulk density decreases with an increase in the feed size, and the specific surface area can further supplement the grinding performance of cylpebs and hexagons. Under the same grinding conditions, the grinding capacity of cylpebs cannot compare with that of cylpebs. However, the grinding effect of hexagons becomes apparent as the particle size of the feed becomes finer and the difference in $\mathrm{P}_{80}$ sizes and $\mathrm{t}_{10}$ values in grinding between hexagons and cylpebs becomes smaller. In addition, the mass content greater than $0.01 \mathrm{~mm}$ in the hexagon-ground product was obviously lower than that in the cylpebs-ground product and there was less overgrinding. These results prove that hexagons, as a grinding media that mainly makes surface contact with minerals, have a good grinding effect on particle minerals, and are helpful in protecting valuable minerals from overgrinding when compared to cylpebs.

When tungsten ore with a particle of size greater than $0.425 \mathrm{~mm}$ was used as a sample for the validation of these results, the same conclusion was obtained. It was theoretically proved that, although the grinding capacity of hexagons is inferior to that of cylpebs, the mass content of qualified grain that is produced by hexagons is as same as cylpebs, and the amount of overgrinding that is produced is lower than that of cylpebs. In addition, the flotation experiment result has carried out that hexagons as grinding media have a better flotation indicator than cylpebs in the same grinding fineness. Thus, compared with cylpebs, hexagons are an excellent choice of grinding media for the grinding of tungsten ore.

Author Contributions: C.W. and N.L. conceived of and designed the experiments; N.L. and L.Z. prepared the samples and performed the experiments; C.W. and N.L. analyzed the data; C.W., N.L., G.S., and L.Z. contributed to the writing and revising of the paper.

Funding: This work is financially supported by the National Natural Science Foundation of China (51764015) and the Jiangxi Provincial Key Research and Development Program of China (S2017YBYFE0475).

Acknowledgments: The authors also thank Hundred Sail Away Project in 2015 provided by Jiangxi Provincial Party Committee Organization Department, the Jiangxi Key Laboratory of Mining Engineering and Hunan Shizhuyuan Nonferrous Metals Co., Ltd., China for their support.

Conflicts of Interest: The authors declare no conflict of interest.

\section{References}

1. Norris, C.C. Some grinding tests with spheres and other shapes. Trans. IMM 1953, 63, 197-209.

2. Duan, X.X. Selective Grinding and Its Application; Metallurgical Industry Press: Beijing, China, 1991. (In Chinese)

3. Wu, C.B. Research on the Application of Crushing Statistical Mechanics Principle and Transition Probability. In The System of Ball Filling; Kunming University of Science and Technology: Kunming, China, 2002. (In Chinese)

4. Cloos, U. Cylpebs: An alternative to balls as grinding media. World Min. 1983, 36, 59.

5. Kiangi, K.; Potapov, A.; Moys, M. DEM validation of media shape effects on the load behaviour and power in a dry pilot mill. Miner. Eng. 2013, 46-47, 52-59. [CrossRef]

6. Herbst, J.A.; LO, Y.C. Grinding Efficiency with Balls or Cones as Media. Int. J. Miner. Process. 1989, 26, 141-151. [CrossRef]

7. Von Kfuger, F.L.; Donda, J.D.; Drummond, M.A.R.; Peres, A.E.C. The effect of using concave surfaces as grinding media. Dev. Miner. Process. 2000, 13, C4-86-C4-93.

8. Shi, F. Comparison of grinding media-Cylpebs versus balls. Miner. Eng. 2004, 17, 1259-1268. [CrossRef]

9. Rittinger, P.R. Lehrbuch der Aufbereitungskunde; Ernst \& Korn: Berlin, Germany, 1867. (In German)

10. Kick, F. Das Gesetz der Proportionalen Winderstands and Seine Anwendug; Springer: Leipzig, Germany, 1885. (In German)

11. Bond, F.C. The third theory of comminution. Trans. AIME 1952, 193, 484-494. 
12. Stamboliadis, E.T. Impact crushing approach to the relationship of energy and particle size in comminution. Eur. J. Miner. Process. Environ. Prot. 2003, 3, 160-166.

13. Stamboliadis, E.T. Energy distribution in comminution, a new approach to the laws of Rittinger, Bond and Kick. Can. Metall. Q. 2004, 43, 249-258. [CrossRef]

14. Stamboliadis, E.T. The energy distribution theory of comminution specific surface energy, mill efficiency and distribution mode. Miner. Eng. 2007, 20, 140-145. [CrossRef]

15. Stamboliadis, E.T. Surface area production during grinding. Miner. Eng. 2009, 22, 587-592. [CrossRef]

16. Shi, G.M.; Zhou, Y.C.; Wu, C.B.; Yang, H.; Zhou, B.; Liu, Y.; Zhao, R.; Zou, C.; Yan, F.; Zhao, J. Double Spherical Hexagonal Prism Grinding Media. CN104888904A, 9 September 2015.

17. Xie, W.; He, Y.; Ge, Z.; Shi, F.; Yang, Y.; Li, H.; Wang, S.; Li, K. An analysis of the energy split for grinding coal/calcite mixture in a ball-and-race mill. Miner. Eng. 2016, 93, 1-9. [CrossRef]

18. Li, C.; Gao, Z. Effect of grinding media on the surface property and flotation behavior of scheelite particles. Powder Technol. 2017, 322, 386-392. [CrossRef]

19. Ulusoy, U.; Kursun, I. Comparison of different 2D image analysis measurement techniques for the shape of talc particles produced by different media milling. Miner. Eng. 2011, 24, 91-97. [CrossRef]

20. Shi, F.; Kojovic, T. Validation of a model for impact breakage incorporating particle size effect. Int. J. Miner. Process. 2007, 22, 156-163. [CrossRef]

21. Shi, F.; Kojovic, T.; Brennan, M. Modelling of vertical spindle mills. Part 1: Sub-models for comminution and classification. Fuel 2015, 143, 595-601. [CrossRef]

22. Shi, F. A review of the applications of the JK size-dependent breakage model Part 1: Ore and coal breakage characterisation. Int. J. Miner. Process. 2016, 155, 118-129. [CrossRef]

23. Shi, F. A review of the applications of the JK size-dependent breakage model Part 2: Assessment of material strength and energy requirement in size reduction. Int. J. Miner. Process. 2016, 157, 36-45. [CrossRef]

24. Shi, F. A review of the applications of the JK size-dependent breakage model Part 3: Comminution equipment modelling. Int. J. Miner. Process. 2016, 157, 60-72. [CrossRef]

25. Standish, N. Optimization of coal grind for maximum bulk density. Powder Technol. 1991, 68, $175-186$. [CrossRef] 